\title{
Renal function in sick very low birthweight infants: 4. Glucose excretion
}

\author{
Barry $\mathrm{H}$ Wilkins
}

\begin{abstract}
Renal glucose excretion was measured on 239 occasions in a sample of 36 infants of 25.5-33 weeks' gestation, birth weight 720-2000 $\mathrm{g}$, between the ages of 0.5 and 32 days. Glucose was invariably present in urine from the first day. Fractional glucose excretion varied widely from $0 \cdot 1 \%$ to $90 \%$ of filtered glucose and glucose excretion rate was up to $15 \cdot 5$ mmol/kg/day and was higher in the most immature infants, especially below 28 weeks' gestation. The highest values were in association with hyperglycaemia between 5 and 15 days but there was no consistent plasma glucose threshold with frequent glucose spillage at normal blood glucose concentrations. There was some correlation with sodium excretion in the first week suggesting that in the absence of hyperglycaemia with a normal filtered glucose load, glucose excretion is caused by proximal tubular immaturity.
\end{abstract}

(Arch Dis Child 1992;67:1162-5)

The clinical management of sick preterm infants includes attention to the daily prescribing of nutrition and maintenance of normal plasma glucose concentration. Urine is frequently tested for the presence of glucose and it is alleged that glucosuria may cause osmotic diuresis and dehydration, ${ }^{1}$ although there is surprisingly little evidence that this is a real danger. It has long been known that premature infants have a lower tubular reabsorption maximum ${ }^{2-11}$ and that glucosuria can be exacerbated by increasing plasma glucose concentration. ${ }^{3}$ This has not been quantified in the sickest and most immature infants in whom glucosuria is observed at normal plasma glucose concentrations.

The purpose of the present investigation was (1) to quantify glucose excretion in sick infants less than 33 weeks' gestation at various ages; (2) to determine whether this may represent significant wastage of glucose energy, and (3) to investigate whether osmotic diuresis is a real possibility.

\section{Patients and methods}

This study was part of a wider study of glomerular and tubular function in very low birthweight infants. ${ }^{12}$ Thirty six were chosen who could be studied in the first postnatal week, and later if possible. Gestation at birth was $25 \cdot 5-33$ weeks, birth weight $720-2000 \mathrm{~g}$.
Further clinical, experimental, and laboratory details are given in Part $1 .{ }^{12}$

Glomerular filtration rate (GFR), plasma glucose concentration, and renal glucose excretion were measured sequentially in 36 infants up to age 3-33 days. Plasma glucose was only measured when plasma was separated from heparinised blood within one hour of collection. GFR and urine flow rate were measured by a continuous infusion Polyfructosan-S (PF-S, Laevosan-Gesellschaft) clearance method. ${ }^{12}$

When PF-S was not being infused urine flow rate was calculated from:

Urine flow rate $=$ creatinine excretion

rate/urine creatinine concentration and GFR from:

$\mathrm{GFR}=$ creatinine excretion rate/plasma creatinine concentration

where creatinine excretion rate is that measured in that baby in nearby PF-S infusion experiments. ${ }^{13}$ Filtered glucose was calculated from:

Filtered glucose $=\mathrm{GFR} \times$ plasma glucose concentration

Fractional glucose excretion $\left(\mathrm{FE}_{\mathrm{Glucose}}\right)$ was calculated from

$$
\begin{aligned}
& \mathrm{FE}_{\mathrm{Glucose}}=\mathrm{U}_{\mathrm{Glucose}} / \mathrm{P}_{\mathrm{Glucose}} \times \mathrm{P}_{\mathrm{PF}-\mathrm{S}} / \mathrm{U}_{\mathrm{PF}-\mathrm{S}} \\
& \mathrm{FE}_{\mathrm{Glucose}}=\mathrm{U}_{\mathrm{Glucose}} / \mathrm{P}_{\mathrm{Glucose}} \times \mathrm{P}_{\mathrm{Cr}} / \mathrm{U}_{\mathrm{Cr}} \times 1 \cdot 101
\end{aligned}
$$

where $1 \cdot 101$ is the mean ratio between PF-S and creatinine $(\mathrm{Cr})$ clearance. ${ }^{14}$ Glucose was measured in undiluted urine, plasma, or aqueous standards by a glucose oxidase/peroxidase photometric method on an Instrumentation Laboratories discrete semiautomated glucose analyser. There were no interfering substances and the coefficient of variation was $2 \%$ at 1 $\mathrm{mmol} / 1$ and $<1.0 \%$ at $10 \mathrm{mmol} / 1$.

\section{Results}

Plasma glucose concentration varied from $1 \cdot 2-13.8 \mathrm{mmol} / 1$ in 262 samples. Only three measurements were $<2 \mathrm{mmol} / \mathrm{l}$ and $15>10$ $\mathrm{mmol} / \mathrm{l}$. Glucose was invariably detected in urine at all ages, 1 to $101 \mathrm{mmol} / \mathrm{l}$ in 329 samples. In only 19 was the glucose concentration $>14 \mathrm{mmol} / 1\left(\frac{1}{4} \%\right)$, in eight $>28 \mathrm{mmol} / 1$ $\left(\frac{1}{2} \%\right)$, and one sample had glucose $>55$ $\mathrm{mmol} / \mathrm{l}(1 \%)$. The great majority of samples had very low glucose concentrations measurable only by laboratory methods and not detectable by ward dipstick testing.

The four graphs contain a mixture of cross sectional and longitudinal data. Fractional glucose excretion $\left(\mathrm{FE}_{\mathrm{Glucose}}\right.$, fig 1$)$ varied from 
$0 \cdot 1 \%$ to $90 \%$ of filtered glucose. Values up to $5 \%$ occurred from the first day in all gestations but most of the highest values, $>10 \%$, are seen from age 5 to 15 days and in the most immature infants below 28 weeks' gesta-

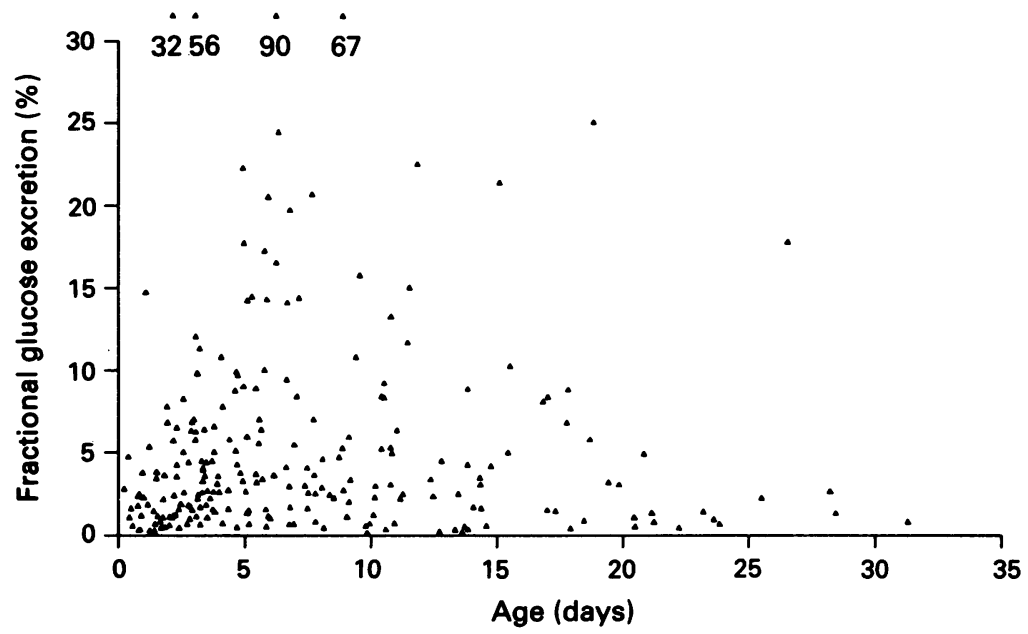

Figure 1 Fractional glucose excretion as a function of postnatal age on 239 occasions in 36 infants ( 82 measurements were made from PF-S infusion experiments and 157 from plasma and urine creatinine and glucose).

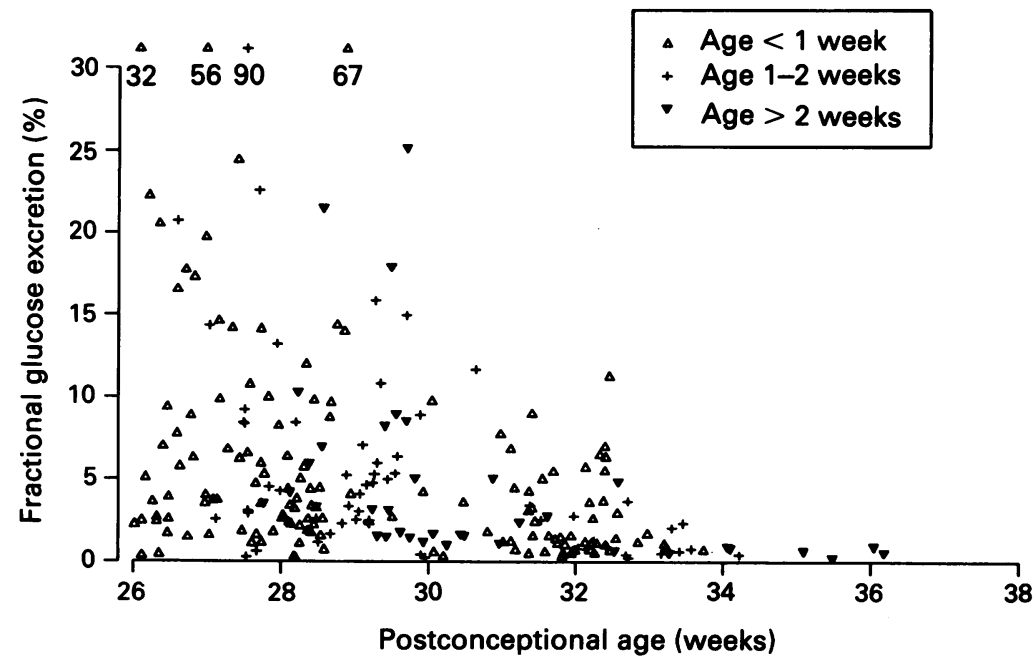

Figure 2 Fractional glucose excretion as a function of postconceptional age in three age groups ( $n=239,143$ at $<1$ week, 59 at 1-2 weeks, 37 at $>2$ weeks).

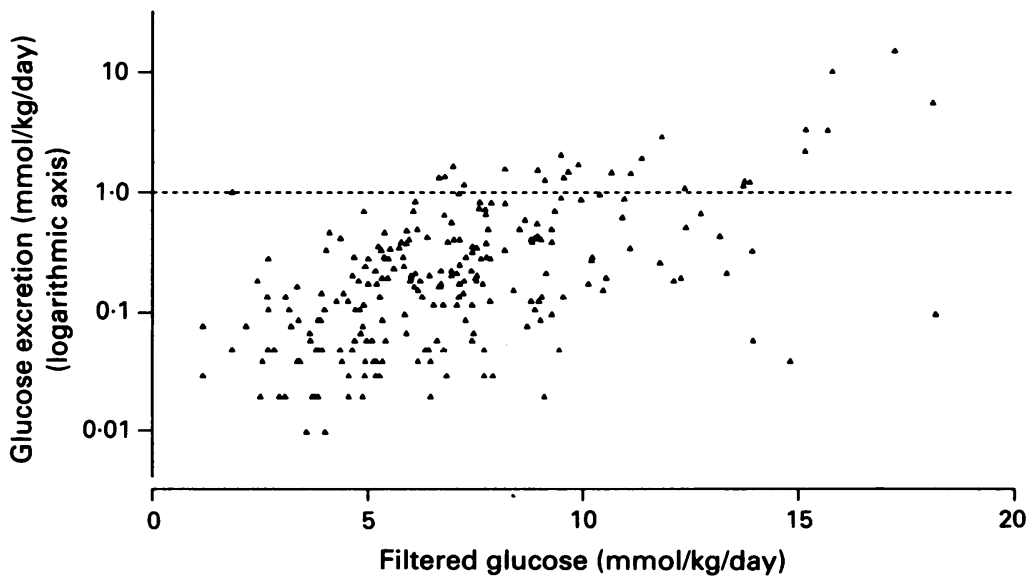

Figure 3 Glucose excretion rate as a function of glucose filtered load ( $n=239)$. On 101 occasions filtered glucose was calculated from $P F-S$ clearance experiments, and on 138 from creatinine. tion at birth (fig 2). Glucose excretion rate $(\mathrm{mmol} / \mathrm{kg} /$ day) had a similar pattern to $\mathrm{FE}_{\text {Glucose }}$ and varied from 0.01 to 15.5 $\mathrm{mmol} / \mathrm{kg} /$ day in 239 measurements, but was $>0.5 \mathrm{mmol} / \mathrm{kg} /$ day in only 50 and $>1$ $\mathrm{mmol} / \mathrm{kg} /$ day in 30 , almost all in infants less than 28 weeks' gestation.

There was no consistent threshold of glucose filtration rate or plasma glucose concentration above which glucose appears in the urine (fig 3). The scattergram is similar whether the abscissa is plasma glucose or filtered glucose, or whether the ordinate is glucose excretion or fractional glucose excretion. Glucose excretion $>0.5 \mathrm{mmol} / \mathrm{kg} /$ day occurred with normal plasma glucose but the highest values, $>2 \mathrm{mmol} / \mathrm{kg} /$ day, only occurred with hyperglycaemia. In the four occasions when excreted glucose was $>4 \mathrm{mmol} / \mathrm{kg} /$ day this represents considerable glucose wastage, approximately $15 \%$ to $35 \%$ of administered glucose, but such occasions were exceptional.

The relationship between glucose excretion and sodium (Na) excretion was complex (fig 4). The highest values of both occurred in the sickest and most immature infants. Low values of glucose excretion occurred at all levels of sodium excretion but the maximum $\mathrm{FE}_{\text {Glucose }}$ increased from negligible to $10 \%$ as $\mathrm{FE}_{\mathrm{Na}}$ increased from zero to $2 \%$. This is not surprising in view of the common proximal tubular reabsorptive mechanism for sodium and glucose, but the highest values of glucose excretion were associated with hyperglycaemia and increased filtered load at age 5-15 days, whereas filtered sodium load is relatively constant between babies and sodium excretion peaked in the first week. ${ }^{15}$

Low levels of glucose excretion occurred at all levels of alveolar-arterial oxygen partial pressure difference $\left(\mathrm{AaDpO}_{2}\right)$ or arterial: alveolar gradient $\left(\mathrm{aApO}_{2}\right.$ ratio). All but two of the high levels of glucose excretion $\left(\mathrm{FE}_{\mathrm{Glucose}}\right.$ $>10 \%$, glucose excretion $>0.5 \mathrm{mmol} / \mathrm{kg} /$ day) occurred when $\mathrm{AaDpO}_{2}$ was $<100 \mathrm{~mm} \mathrm{Hg}$ $(13.3 \mathrm{kPa})$ or aApo2 ratio $>0.3$, and almost always during the recovery period after severe respiratory illness.

The few instances of high urine glucose concentration ( $>28 \mathrm{mmol} / 1,0 \cdot 25 \%)$ and high glucose excretion $(>3 \mathrm{mmol} / \mathrm{kg} /$ day $)$ were always isolated and not repeated in any baby. However, prolonged glucose excretion $>1$ $\mathrm{mmol} / \mathrm{kg} /$ day occurred in five infants $<28$ weeks' gestation for periods of three to eight days when plasma glucose concentration was $5-13 \mathrm{mmol} / \mathrm{l}$ and urine glucose $6-101 \mathrm{mmol} / \mathrm{l}$. Most of these occasions were associated with a secondary illness, usually with signs suggestive of necrotising enterocolitis or acute sepsis which was proved in three cases. Sometimes sodium excretion secondarily increased as well but not all instances of sepsis were accompanied by hyperglycaemia and/or high glucose excretion.

No obvious osmotic diuresis was observed in association with high urine glucose but it cannot be excluded because urine flow rate can vary widely from day to day irrespective of glucose excretion. ${ }^{15}$ The table details indices 


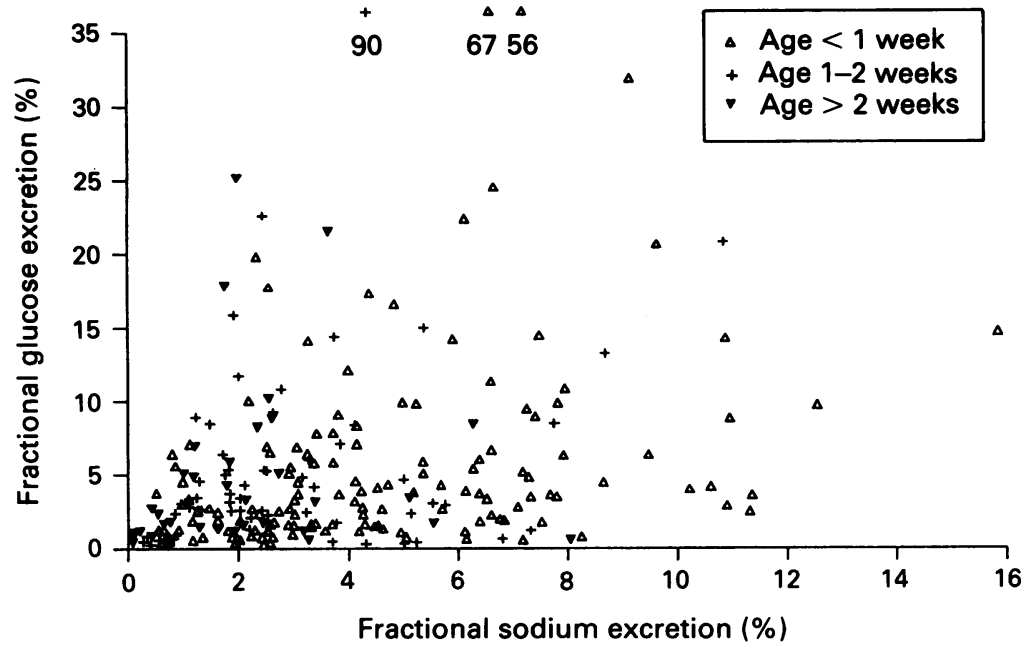

Figure 4 Fractional glucose excretion as a function of sodium excretion in three age groups.

Indices for the eight urine samples in eight patients with the highest urine glucose concentrations

\begin{tabular}{|c|c|c|c|c|c|c|c|}
\hline $\begin{array}{l}\text { Urine } \\
\text { glucose } \\
\text { (mmoll) }\end{array}$ & $\begin{array}{l}\text { Plasma } \\
\text { glucose } \\
\text { (mmoll) }\end{array}$ & $\begin{array}{l}\text { Urine } \\
\text { osmolality } \\
\text { (mosmoll) }\end{array}$ & $\begin{array}{l}\text { Urine } \\
\text { sodium } \\
\text { (mmoll) }\end{array}$ & $\begin{array}{l}\text { Urine } \\
\text { urea } \\
\text { (mmoll) }\end{array}$ & $\begin{array}{l}\text { Urine } \\
\text { flow rate } \\
\text { (ml/kg/day) }\end{array}$ & $\begin{array}{l}\text { Glucose } \\
\text { excretion } \\
\text { (mmolkg/ } \\
\text { day) }\end{array}$ & $\begin{array}{l}\text { Total } \\
\text { osmolar } \\
\text { excretion } \\
\text { (mosmol/kg/day) }\end{array}$ \\
\hline $\begin{array}{r}101 \\
52 \\
45 \\
41 \\
40 \\
32 \\
29 \\
29\end{array}$ & $\begin{array}{c}13 \cdot 8 \\
13 \\
13 \cdot 4 \\
8 \\
13 \\
10 \\
7 \\
13\end{array}$ & $\begin{array}{l}327 \\
192 \\
482 \\
350 \\
196 \\
140 \\
122 \\
310\end{array}$ & $\begin{array}{r}42 \\
56 \\
142 \\
99 \\
43 \\
70 \\
16 \\
54\end{array}$ & $\begin{array}{l}62 \\
19 \\
86 \\
68 \\
10 \\
20 \\
19 \\
26\end{array}$ & $\begin{array}{r}153 \\
202 \\
129 \\
43 \\
88 \\
106 \\
245 \\
42\end{array}$ & $\begin{array}{r}15.5 \\
10.5 \\
5.8 \\
1.8 \\
3.5 \\
3.4 \\
7.1 \\
1.2\end{array}$ & $\begin{array}{l}50 \\
39 \\
62 \\
11 \\
17 \\
15 \\
30 \\
13\end{array}$ \\
\hline
\end{tabular}

for the eight occasions when urine glucose concentration was greater than $28 \mathrm{mmol} / \mathrm{l}$. Glucose accounted for up to $31 \%$ of excreted solute, the rest being mainly sodium chloride and urea. Urine osmolality was always well within the normal range.

\section{Discussion}

The normal, mature kidney excretes only very small quantities of glucose, the fractional excretion by the renal tubule being close to $0 \% .^{16} 17$ Glucose only appears in the urine when the plasma glucose concentration increases above the threshold for saturation of the tubular transport mechanism. ${ }^{3469}$ A low glucose threshold is often assumed in the preterm, but in the present study it is very variable even without hyperglycaemia. Although glucose excretion was low in the majority of samples tested, significant glucose spillage can occur when the plasma glucose concentration is normal and urine glucose concentration is only $\frac{1}{4}-\frac{1}{2} \%$, which would normally be ignored in clinical practice. This may represent up to $35 \%$ of the glucose energy administered to the infant $(6 \mathrm{mg} / \mathrm{kg} / \mathrm{min}$ glucose input $=48 \mathrm{mmol} / \mathrm{kg} /$ day) and so exceptionally it may represent significant energy wastage. This is nevertheless negligible in the majority of samples tested.

Although glucose reabsorption in the proximal tubule depends on $\mathrm{Na} / \mathrm{K}$ ATPase this failure to conserve glucose does not parallel sodium excretion. Failure of glucose conservation implies proximal rather than distal tubular dysfunction, whereas failure of sodium reabsorption may occur in all parts of the tubule which may account for some instances of high $\mathrm{FE}_{\mathrm{Na}}$ but low $\mathrm{FE}_{\mathrm{Glucose}}$. Developmental studies in the rabbit have shown that glucose and bicarbonate reabsorption mature before sodium. ${ }^{8} 18$ It is likely that in the absence of hyperglycaemia failure of glucose reabsorption is caused by failure of sodium reabsorption in the proximal tubule and depends on the degree of tubular immaturity. It cannot be due to volume expansion ${ }^{19}$ because most of these infants are volume contracted.

The present results for glucose excretion are higher than previously reported in less ill and more mature infants ${ }^{4-7}$ but similar to those of one previous study which reported up to $45 \% \mathrm{FE}_{\text {Glucose }}$ in sick ventilated newborns. $^{20}$ They also reported no difference between stable and unstable ventilated infants (no measure of respiratory severity was given) but much lower levels in unventilated infants. These and the present results suggest that sickness, such as sepsis but not respiratory disease, as well as immaturity contribute to failure of tubular glucose reabsorption.

High levels of excretion of filtered solute that the tubules cannot reabsorb may cause an obligatory increase in flow of filtered water through the nephron, an osmotic diuresis. Either exogenously administered osmotic agents, which increase plasma osmolality and therefore the filtered osmolar load, or the failure of the tubule to reabsorb a specific solute such as glucose, may have this effect. The presence of unreabsorbable osmoles such as glucose in the proximal tubule inhibits the reabsorption of water which normally follows the active sodium chloride reabsorption. ${ }^{21}$ In turn this leads to an increased flow rate through the tubule and a decrease in the sodium chloride concentration in the tubular fluid. These effects combine to reduce or even eliminate the medullary concentration gradient. Water reabsorption in the collecting duct may therefore be minimal even in the presence of a high concentration of antidiuretic hormone. Under conditions of maximal osmotic diuresis the urine osmolality approaches that of plasma whether there is pre-existing dehydration or pre-existing water diuresis. An osmotic diuresis caused by an increased excretion of osmoles is usually associated with a change in urine osmolality away from the extremes. Therefore osmotic diuresis cannot be excluded on the basis of normal urine osmolality despite a suggestion otherwise. ${ }^{20}$

It is possible, therefore, that on the rare occasions when glucose makes a significant contribution to an abnormally high total osmolar excretion it may cause an obligatory increase in water excretion.

In clinical practice this will not matter so long as clinicians pay attention to adjusting water input according to estimated water excretion (from random urine creatinine ${ }^{13}$ ) and weight change. Moreover, there is little value in measuring urine glucose; it is more important to maintain normal plasma glucose concentration by adjusting glucose input. 
This work was funded by the Children Nationwide Medical Research Fund, and the Southmead Research Foundation, Southmead Hospital, Bristol. The author is grateful to Mrs N Kingston and Mrs $M$ Williams for performing some of the laboratory work, to Dr B Speidel, Dr P Fleming, and Professor $\mathrm{P}$ Dunn for allowing their patients to be studied, Dr T Chambers for continual encouragement, and Dr J P Midgley for inspiration in the final stages of writing.

1 Roberton NRC. A manual of neonatal intensive care. London: Edward Arnold, 1986:40.

2 Alexander DP, Nixon DA. Reabsorption of glucose, fructose and mesoinositol by the fetal and postnatal sheep tose and mesoinositol by the
kidney. $\mathcal{F}$ Physiol 1963;167:480.

3 Stonestreet BS, Rubin L, Pollack A, Cowett RM, Oh W. Renal functions of low birth weight infants with hyperglycaemia and glucosuria produced by glucose infusions. 1980;66:561-7.

4 Leake RD, Oh W. Effect of gestational age on glomerular filtration rate and tubular maxima of glucose in human infants (abstract). Pediatr Res 1974;8:457/183.

5 Brodehl JA, Franken A, Gellisen K. Maximal tubular reabsorption of glucose in infants and children. Acta Paediatr Scand 1972;61:413-20.

6 Tudvad F, Vesterdal J. The maximal transfer of glucose and para-aminohippurate in premature infants. Acta Paediatr Scand 1953;42:337-45.

7 Tudvad F, Vesterdal J. Sugar reabsorption in premature and full term babies. Scand $f$ Clin Lab Invest 1949;1: 281-3.

8 Schwartz GJ, Evan AP. Development of solute transport in rabbit proximal tubule. I. Bicarbonate and glucose reabsorption. Am f Physiol 1983;245:F382-90.

9 Arant BS. Developmental patterns of renal functional mat- uration compared in the human neonate. $f$ Pediatr 1978; 92:705-12

$10 \mathrm{Oh} \mathrm{W}$. Renal function and clinical disorders in the neonate. Clin Perinatol 1981;8:215-23.

11 Haworth JC, MacDonald MS. Reducing sugars in urine and blood of premature babies. Arch Dis Child 1957; 32:417-21

12 Wilkins BH. Renal function in sick very low birthweight infants: 1. Glomerular filtration rate. Arch Dis Child 1992;67:1140-5.

13 Wilkins $\mathrm{BH}$. Renal function in sick very low birthweight infants: 2. urea and creatinine excretion. Arch Dis Child 1992;67: 1146-53.

14 Wilkins BH. A reappraisal of the measurement of glomerular filtration rate in pre-term infants. Pediatr Nephrol lar filtration rate

15 Wilkins BH. Renal function in sick very low birthweight infants: 3. Sodium, potassium and water excretion. Arch Dis Child 1992;

16 Barfuss DW, Schafer JA. Differences in active and passive glucose transport along the proximal nephron. $A m \quad f$ Physiol 1981;241:F322-32.

17 Aronson $\mathrm{P}$, Sacktor $\mathrm{B}$. The $\mathrm{Na}^{+}$gradient-dependent transport of D-glucose in renal border membranes. $f$ Biol Chem 1975;250:6032-9.

18 Schwartz G, Evan AP. Development of solute transport in rabbit proximal tubule. III. Na-K-ATPase activity. $\mathrm{Am}^{\mathrm{f}}$ Physiol 1984;246:F845-52.

19 Arant BS. Non renal factors influencing renal function. Clin Perinatol 1981;8:225-40.

20 Coulthard MG, Hey EN. Differences in renal tubular glucose handling between well and sick newborns [abstract] Pediatr Nephrol 1989;3:C53.

21 Gennari FI, Kassirer JP. Osmotic diuresis. N Engl f Med 1974 291:714-20. 